\title{
A multi nutrient concept to enhance synapse formation and function: science behind a medical food for Alzheimer's disease
}

\author{
John W.C. SIJBEN ${ }^{1}$ \\ Martijn C. DE WILDE ${ }^{1}$ \\ Rico WIEGGERS ${ }^{1}$ \\ Martine GROENENDIJK ${ }^{1}$ \\ Patrick J.G.H. KAMPHUIS ${ }^{1,2}$ \\ ${ }^{1}$ Nutricia Advanced Medical Nutrition, \\ Danone Research, \\ Centre for Specialised Nutrition, \\ P.O. Box 7005, \\ 6700 CA Wageningen, \\ The Netherlands \\ $<$ john.sijben@nutricia.com> \\ ${ }^{2}$ Utrecht Institute for Pharmaceutical \\ Sciences (UIPS), Utrecht University, \\ The Netherlands
}

\begin{abstract}
Alzheimer's Disease $(A D)$ is the leading cause of dementia. Epidemiological studies suggest that $A D$ is linked with poor status of nutrients including $D H A, B$-vitamins and the vitamins $E$ and $C$. Ongoing neurodegeneration, particularly synaptic loss, leads to the classical clinical features of $A D$ namely, memory impairment, language deterioration, and executive and visuospatial dysfunction. The main constituents of neural and synaptic membranes are phospholipids. Supplemenation of animals with three dietary precursors of phospholipids namely, DHA, uridine monophosphate and choline, results in increased levels of brain phospholipids, synaptic proteins, neurite outgrowth, dendritic spines formation (i.e. the anatomical precursors of new synapses) and an improvement in learning and memory. Other nutrients act as co-factors in the synthesis pathway of neuronal membranes. For example B-vitamins are involved in methylation processes, thereby enhancing the availability of choline as a synaptic membrane precursor. A multi-nutrient concept that includes these nutrients may improve membrane integrity, thereby influencing membrane-dependent processes such as receptor function and amyloid precursor protein (APP) processing, as shown by reduced amyloid production and amyloid $\beta$ plaque burden, as well as toxicity. Together, these insights provided the basis for the development of a medical food for patients with $A D$, Souvenaid ${ }^{\mathbb{R}}$, containing a specific combination of nutrients (Fortasyn ${ }^{T M}$ Connect) and designed to enhance synapse formation in $A D$. The effect of Souvenaid on memory and cognitive performance was recently assessed in a proof-of-concept study, SOUVENIR I, with 212 drug-naive mild AD patients (MMSE 20-26). This proof-of-concept study

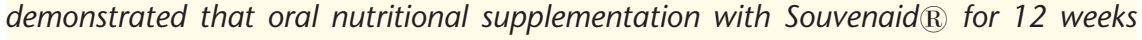
improves memory in patients with mild $A D$. To confirm and extend these findings, we have designed and initiated three additional studies. Two of these studies will be completed in 2011; Souvenir II, a 24-week European study, with 259 drug-naive mild AD patients (MMSE $\geq 20$ ) and S-Connect, another 24-week study, with 527 mild-tomoderate AD patients (MMSE 14-24) using AD medication conducted in the US. The third is the EU-funded LipiDiDiet study, a 24-month study, which will enrol 300 people with prodromal $A D$ to assess the effect on memory performance.
\end{abstract}

Key words: Alzheimer's disease, nutrition, souvenaid, synapse, membrane, phospholipids

by 2050 (ADI, 2010). Age is the primary risk factor (von Strauss et al., 1999; Citron, 2002), while the primary genetic risk factors include family history of $\mathrm{AD}$ (for familial $A D$ ) and presence of the apolipoprotein $\mathrm{E}-\varepsilon 4$ genotype (apoE4, for sporadic AD) (Fratiglioni et al., 1993; Seshadri et al., 1995). Furthermore, increasing epidemiological evidence suggests diet as one of the most important modifiable risk factors (Engelhart et al., 2002; Morris et al., 2003). Other aspects of disease aetiology, including vascular and psychosocial is expected to increase to 115.4 million

To cite this article: Sijben JWC, de Wilde MC, Wieggers R, Groenendijk M, Kamphuis PJGH. A multi nutrient concept to enhance synapse formation and function: science behind a medical food for Alzheimer's disease. OCL 2011; 18(5): 267-270. doi : 10.1684/ocl.2011.0410 
factors, are under investigation (Qiu et al., 2009).

The exact cause of $A D$ remains unknown, despite decades of research guided by several hypotheses based upon differing brain pathologies. Amyloid plaques, neurofibrillary tangles and progressive loss of neurons are characteristic hallmarks of $A D$ that allow for post-mortem histological confirmation of the condition. However, severe synaptic loss and/ or reduced synaptic activity and connectivity in specific brain areas occurs early in the disease process resulting in the classic clinical features of AD: memory impairment, language deterioration, and executive and visuospatial dysfunction (Terry and Katzman, 2001; Scheff and Price, 2006). Soluble beta-amyloid (A $\beta$ ) protein oligomers have been proposed as the pathogenic agents that induce loss of synaptic and dendritic spines in $A D$ (Haass and Selkoe, 2007; Shankar et al., 2007; Shankar et al., 2008; Freir et al., 2010). It has been reported that symptomatic dementia occurs when there is an approximately $40 \%$ reduction in cortical synapses compared with agematched healthy adults (Terry et al., 1991). Synapse loss is the strongest structural correlate with cognitive performance in $A D$, even more so than the prevalence of plaques or tangles (Terry et al., 1991; Terry, 2006). Therefore, improving synaptic formation and function may well be a target for intervention in $\mathrm{AD}$.

\section{Enhancing neuronal membrane and synapse formation and function with nutrients}

Synapses are highly specialized membrane structures that form the contact points enabling information exchange between neurons. Synapses typically consist of an axonal presynaptic nerve terminal, a synaptic cleft, and a postsynaptic membrane, usually on a dendrite or cell body. New brain synapses form when a postsynaptic structure, the dendritic spine, interacts with a presynaptic nerve terminal (Toni et al., 2007). Since dendritic spine growth precedes synapse formation and new synapses form preferentially onto existing boutons (Knott et al., 2006), the rate of synaptogenesis depends, at least in part, on the numbers of available dendritic spines. The membranes of dendritic spines and synapses are composed of phospholipids and contain synaptic proteins. Phospholipids are generated primarily via the cytidine diphosphate (CDP)choline and CDP-ethanolamine pathways of the Kennedy cycle (Kennedy and Weiss, 1956). The formation of phospholipids in the brain is dependent upon an adequate supply of circulating dietary compounds, because nutrients increasing the substrate-saturation of low-affinity enzymes that synthesize the phospholipids (Wurtman et al., 2009). Thus, increasing brain phospholipid levels by dietary means could increase the quantity of the brain membranes. Indeed, animals given three of these precursors, uridine, DHA, and choline, develop increased levels of brain phospholipids (Wurtman et al., 2006; Cansev and Wurtman, 2007; Sakamoto et al., 2007a; Cansev et al., 2008; Holguin et al., 2008b; Holguin et al., 2008a; Cansev et al., 2009). For example, gerbils receiving a daily diet containing choline $(0.1 \%)$ and uridine monophosphate (UMP, $0.5 \%$ ) or DHA (300 mg/kg) by gavage for 4 weeks showed up to a $22 \%$ increase in brain phosphotidylcholine (PC) levels. Interestingly, combining the three nutrients (choline, UMP, DHA) increased brain PC levels by $45 \%$, and the other phospholipid classes by up to $74 \%$ (Wurtman et al., 2006). Thus, while providing the single nutrients clearly increases brain phospholipid levels, the largest increases are obtained when all three precursors are combined. Combined supplementation of choline, UMP, and DHA was also found to increase brain levels of specific proteins such as synapsin-1, PSD-95, and syntaxin-3, known to be localized within presynaptic and postsynaptic membranes. However, dietary intervention had no effect on the cytoskeletal protein beta-tubulin, indicating a selective increase in synaptic membrane. The effects of DHA and UMP supplementation on dendritic spine number were examined in adult gerbils treated daily for 1-4 weeks; animals received single or combined compounds (Sakamoto et al., 2007b). DHA alone caused doserelated increases in spine density, accompanied by parallel increases in membrane phospholipids and in specific pre- and postsynaptic proteins; its effect was doubled if animals also received UMP. Administration of DHA, UMP, and choline to normal adult animals improved hippocampus-dependent cog- nitive behaviors in rats (Teather and Wurtman, 2006; Holguin et al., 2008b) and gerbils (Holguin et al., 2008a). These findings suggest that a nutrient supplementation that increases synaptic membrane and dendritic spine formation in the brain enhances cognitive processes associated with synaptic functioning.

B-vitamins, phospholipids and antioxidants serve as co-factors by enhancing the availability of these precursors (van Wijk et al., 2011). Combined dietary enrichment with these nutrients has also been shown to influence membranedependent processes, e.g. reducing amyloid precursor processing (APP) pathways and receptor function. This, in turn, could result in reduced $A \beta$ production, plaque burden and $A \beta$ toxicity (Broersen et al., 2007). Additional data suggest that this multinutrient combination protects the cholinergic system against $A \beta_{42}$-induced toxicity (de Wilde et al., 2011b). In support of this, epidemiological and cohort studies indicate that a diet rich in omega- 3 fatty acids, B-vitamins, and antioxidants decreases the risk of $A D$ (Barberger-Gateau et al., 2007; Luchsinger et al., 2007), while others have reported lower plasma levels of these nutrients in patients with $A D$ compared with cognitively intact age-matched controls (Shatenstein et al., 2007).

\section{Proof of concept and future directions}

The observations described in the previous section led to the development of Souvenaid ${ }^{\mathbb{R}}$, a multi-nutrient drink designed to deliver the supporting nutrients to improve synaptic membrane formation and function in patients with AD. This medical food contains a specific formulation of nutrients registered as Fortasyn $^{\mathrm{TM}}$ Connect (including DHA, EPA, phospholipids, choline, UMP, vitamin $B 12, B 6$, and folate, vitamins $C$ and $E$ and selenium) (Scheltens et al., 2010). The efficacy and tolerability of Souvenaid was recently assessed in 225 drug-naive mild AD patients (MMSE 20-26) in a multicenter, controlled, proof-of-concept Souvenir I study (Scheltens et al., 2010). The study was a 12-week randomized, double-blind, controlled, parallel-group, multi-centre, multi-country study, with a 12-week similarly designed exploratory extension period, in which patients received the same study product as in the first 12 weeks 
of the study. Patients were randomly assigned to active product (Souvenaid) or an isocaloric control drink, taken oncedaily for 12 weeks. After 12 weeks, patients were invited to continue in an optional 12-week extension study. Blood samples from patients completing the 24 week program were used to analyze plasma or erythrocyte levels of nutrients. Compliance was excellent (94\%) and this was biochemically confirmed by marked increase of DHA and EPA levels in the erythrocyte membranes and reduced plasma homocysteine. The results of the study also demonstrated a very favorable safety profile for Souvenaid with no differences between the Souvenaid and control group in the incidence of either adverse events or serious adverse events. Furthermore, no difference was observed between the active and control group in biochemical safety markers of liver and renal function). At 12 weeks, a significant improvement in the Wechsler Memory Scale-revised (WMS-r) delayed verbal recall score (co primary outcome measure) was noted in the Souvenaid group compared with control ( $\mathrm{p}=$ 0.021 ). The other co-primary outcome measure, Modified Alzheimer's Disease Assessment Scale-cognitive (ADAS-cog) subscale, and secondary outcome scores (e.g., Clinician Interview Based Impression of Change plus Caregiver Input, 12-item Neuropsychiatric Inventory, Alzheimer's disease Co-operative StudyActivities of Daily Living, Quality of Life in Alzheimer's Disease) were unchanged. In a pre-specified subgroup analysis of patients with very mild AD (baseline MMSE 24-26), daily intake of Souvenaid for 12 weeks resulted in an improved memory performance compared with the control. Both immediate and delayed verbal memory scores were significantly improved $(p=0.011)$ in this pre-specified sub-group. In addition to effects on delayed and immediate memory performance at 12 weeks, a significant improvement in the immediate but not in the delayed verbal recall task was noted in the active group compared with control after 24 weeks intervention. The Souvenir I study was primarily designed to study effects after 12 weeks intervention (de Wilde et al., 2011a). It should be taken into account that the extension period had an exploratory character and aimed to obtain additional efficacy, tolerability and safety data during a longer period. Post hoc analysis indicated a significant positive effect on Activities of Daily Living (ADL) after 12 weeks for the subgroup of AD patients with a body mass index (BMI) below the mean of the total group (Kamphuis et al., 2011b). Finally, in secondary analysis a significant treatment effect on ADAS-cog was shown in patients with "high" baseline ADAS-cog, but not in patients with 'low' baseline ADAS-cog (Kamphuis et al., 2011a).

To confirm and extend the initial findings of the efficacy and safety of Souvenaid, three additional randomized doubleblind controlled studies were started in 2009. The 'S-Connect' study (NTR1683) is a 24-week randomized, controlled, double-blind, study in > 500 mild-tomoderate AD subjects (MMSE 14-24) using $A D$ medication across 48 sites in the United States. The 'Souvenir II' study (NTR1975) is a 24-week randomized, controlled, double-blind, European study in 226 drug naïve mild AD subjects (MMSE $\geq 20$ ) across 27 centers in The Netherlands, Belgium, Germany, France, Spain and Italy. Finally, the "LipiDiDiet study" (NTR1705), is a 24-month randomized, controlled, double-blind, study in 300 prodromal AD subjects (MMSE $\geq 24$ ). Results of these studies are expected to be available between 2011 and 2014.

In conclusion, Souvenaid is a multinutrient drink designed to improve the formation and function of synapses in AD. A proof-of-concept study indicated that memory performance in drug naïve mild AD was improved. Clinical studies to confirm and extend this finding are ongoing.

\section{Disclosure statements}

Financial support: The research has received funding from the EU FP7 project LipiDiDiet, Grant Agreement № 211696. JS, MW, RW, MG and PK are employees of Nutricia Advanced Medical Nutrition, Danone Research, Centre for Specialised Nutrition, Wageningen, The Netherlands. JS, MW, RW, MG and PK are mentioned as inventor on patents and patent applications owned by Nutricia. Some of the studies mentioned in this publication have been partly funded by Nutricia.

\section{REFERENCES}

ADI. World Alzheimer report 2010: The global economic impact of dementia. In:
Accessed 25 May 2011 at http://www.alz.co. uk/research/files/WorldAlzheimerReport2010 ExecutiveSummary.pdf. 2010.

Barberger-Gateau P, Raffaitin C, Letenneur L, et al. Dietary patterns and risk of dementia: the Three-City cohort study. Neurology 2007; 69: 1921-30.

Broersen LM, De Wilde MIL, Kuipers AAM, Van Wijk NW, Kamphuis PJ, Van der Beek EM. Reduced beta-amyloid plaque burden and neurodegeneration in APP/PS1 transgenic mice following multi-nutrient dietary intervention. Society for Neuroscience (San Diego, CA) Programme number 157.116/U127.2007.

Cansev M, Wurtman RJ. Chronic administration of docosahexaenoic acid or eicosapentaenoic acid, but not arachidonic acid, alone or in combination with uridine, increases brain phosphatide and synaptic protein levels in gerbils. Neuroscience 2007; 148: 421-31.

Cansev M, Ulus IH, Wang L, Maher TJ, Wurtman RJ. Restorative effects of uridine plus docosahexaenoic acid in a rat model of Parkinson's disease. Neurosci Res 2008; 62: 206-9.

Cansev M, Marzloff G, Sakamoto T, Ulus IH, Wurtman RJ. Giving uridine and/or docosahexaenoic acid orally to rat dams during gestation and nursing increases synaptic elements in brains of weanling pups. Dev Neurosci 2009; 31: 181-92.

Citron M. Alzheimer's disease: treatments in discovery and development. Nat Neurosci 2002;(Suppl 5):1055-1057.

de Wilde MC, Kamphuis P, Sijben JWC, Scheltens P. Utility of imaging for nutritional intervention studies in Alzheimer's disease. European Journal of Pharmacology. Article online. 2011a.

de Wilde MC, Penke B, van der Beek EM, Kuipers AAM, Kamphuis PJ, Broersen LM. Neuroprotective effects of a specific multinutrient intervention against $A ß 42$-induced toxicity in rats. Journal of Alzheimers disease. 2011b.

Engelhart MJ, Geerlings MI, Ruitenberg A, et al. Dietary intake of antioxidants and risk of Alzheimer disease. JAMA 2002; 287: 3223-9.

Fratiglioni L, Ahlbom A, Viitanen M, Winblad B. Risk factors for late-onset Alzheimer's disease: a population-based, case-control study. Ann Neurol 1993; 33: 258-66.

Freir DB, Fedriani R, Scully D, Smith IM, Selkoe DJ, Walsh DM, Regan CM. Abeta oligomers inhibit synapse remodelling necessary for memory consolidation. Neurobiol Aging 2010; doi:10.1016/j.neurobiolaging. 2010.01.001

Haass C, Selkoe DJ. Soluble protein oligomers in neurodegeneration: lessons from the Alzheimer's amyloid beta-peptide. Nat Rev Mol Cell Biol 2007; 8: 101-12. 
Holguin S, Martinez J, Chow C, Wurtman R. Dietary uridine enhances the improvement in learning and memory produced by administering DHA to gerbils. Faseb / 2008; 22: 3938-46.

Holguin S, Huang Y, Liu J, Wurtman R. Chronic administration of DHA and UMP improves the impaired memory of environmentally impoverished rats. Behav Brain Res 2008; 191: 11-6.

Kamphuis $\mathrm{P}$, Verhey FRJMD, Olde Rikkert MGM, Twisk JWR, Swinkels SHN, Scheltens P. Efficacy of a medical food on cognition in Alzheimer's disease: results from secondary analyses of a randomized, controlled trial. The Journal of Nutrition, Health \& Aging. 2011 a.

Kamphuis P, Verhey FRJ, Old Rikkert MGM, Twisk JWR, Swinkels SHN, Scheltens $P$. Effect of a medical food on body mass index and activities of daily living in patients with Alzheimer's disease: secondary analyses from a randomized, controlled trial. Journal of Nutrition Health and Aging. 2011 b.

Kennedy EP, Weiss SB. The function of cytidine coenzymes in the biosynthesis of phospholipides. J Biol Chem 1956; 222: 193214.

Knott GW, Holtmaat A, Wilbrecht L, Welker E, Svoboda K. Spine growth precedes synapse formation in the adult neocortex in vivo. Nat Neurosci 2006; 9: 1117-24.

Luchsinger JA, Tang MX, Miller J, Green R, Mayeux R. Relation of higher folate intake to lower risk of Alzheimer disease in the elderly. Arch Neurol 2007; 64: 86-92.

Morris MC, Evans DA, Bienias JL, et al. Dietary fats and the risk of incident Alzheimer disease. Arch Neurol 2003; 60: 194-200.
Qiu C, Kivipelto M, von Strauss E. Epidemiology of Alzheimer's disease: occurrence, determinants, and strategies toward intervention. Dialogues Clin Neurosci 2009; 11: 111-28.

Sakamoto T, Cansev M, Wurtman RJ. Oral supplementation with docosahexaenoic acid and uridine-5'-monophosphate increases dendritic spine density in adult gerbil hippocampus. Brain Res 2007; 1182: 50-9.

Scheff SW, Price DA. Alzheimer's diseaserelated alterations in synaptic density: neocortex and hippocampus. I Alzheimers Dis 2006; 9: 101-15.

Scheltens P, Kamphuis PJ, Verhey FR, et al. Efficacy of a medical food in mild Alzheimer's disease: A randomized, controlled trial. Alzheimers Dement 2010; 6: 1-10 e11.

Seshadri S, Drachman DA, Lippa CF. Apolipoprotein E epsilon 4 allele and the lifetime risk of Alzheimer's disease. What physicians know and what they should know Arch Neurol 1995; 52: 1074-9.

Shankar GM, Bloodgood BL, Townsend M, Walsh DM, Selkoe DJ, Sabatini BL. Natural oligomers of the Alzheimer amyloid-beta protein induce reversible synapse loss by modulating an NMDA-type glutamate receptor-dependent signaling pathway. I Neurosci 2007; 27: 2866-75.

Shankar GM, Li S, Mehta TH, et al. Amyloidbeta protein dimers isolated directly from Alzheimer's brains impair synaptic plasticity and memory. Nat Med 2008; 14: 837-42.

Shatenstein B, Kergoat MJ, Reid I. Poor nutrient intakes during 1-year follow-up with community-dwelling older adults with earlystage Alzheimer dementia compared to cognitively intact matched controls. I Am Diet Assoc 2007; 107: 2091-9.
Teather LA, Wurtman RJ. Chronic administration of UMP ameliorates the impairment of hippocampal-dependent memory in impoverished rats. J Nutr 2006; 136: 2834-7.

Terry RD. Alzheimer's disease and the aging brain. / Geriatr Psychiatry Neurol 2006; 19: 125-8.

Terry RD, Katzman R. Life span and synapses: will there be a primary senile dementia? Neurobiol Aging 2001; 22: 347-8; discussion 353-344.

Terry RD, Masliah E, Salmon DP, et al. Physical basis of cognitive alterations in Alzheimer's disease: synapse loss is the major correlate of cognitive impairment. Ann Neurol 1991; 30: 572-80.

Toni N, Teng EM, Bushong EA, et al. Ellisman $\mathrm{MH}$, Gage FH. Synapse formation on neurons born in the adult hippocampus. Nat Neurosci 2007; 10: 727-34.

van Wijk N, Watkins Cl, Böhlke $M$, et al. Dietary levels of vitamins B6, B12, and folic acid affect plasma choline concentration in rats fed a choline adequate diet. British Journal of Nutrition. 2011.

von Strauss $E$, Viitanen $M$, De Ronchi $D$, Winblad B, Fratiglioni L. Aging and the occurrence of dementia: findings from a population-based cohort with a large sample of nonagenarians. Arch Neurol 1999; 56: 587-92.

Wurtman RJ, Cansev M, Sakamoto T, Ulus IH. Use of phosphatide precursors to promote synaptogenesis. Annu Rev Nutr 2009; 29: 59-87.

Wurtman RJ, Ulus IH, Cansev M, Watkins CJ, Wang L, Marzloff G. Synaptic proteins and phospholipids are increased in gerbil brain by administering uridine plus docosahexaenoic acid orally. Brain Res 2006; 1088: 83-92. 